\title{
Vertrauen \\ ohne Kontrolle
}

\section{Liebe Leserin, lieber Leser,}

wissen Sie, was Erdbeeren, Puppenhäuser und Katzenfutter gemeinsam haben? Nun, diese Produkte wurden mit der Post an ahnungslose Zeitgenossen geliefert. Schuld war der Amazon-Lautsprecher, der auf Stichwort „Alexa“ hin seine Funktion aufnimmt. Und dabei kann es zu lustigen Pannen wie diesen kommen. Weniger lustig ist es, wenn Alexa Aufnahmen aus dem Schlafzimmer an fremde Personen verschickt, was auch schon passiert ist. Wir haben es hier ergo mit Fällen unerwünschten Eingreifens und einem erheblichen Mangel an Datensicherheit bei einem Assistenzsystem, genauer gesagt bei einer Schnittstelle zwischen Mensch und Maschine, zu tun.

Für Mensch-Maschine-Schnittstellen im Bereich Automotive, die Insassen eines Pkw immer mehr Möglichkeiten zur Interaktion mit den Fahrzeugfunktionen bieten, muss ein höheres Maß in Sachen Zuverlässigkeit als auf dem heimischen Sofa angelegt werden. Schließlich bewegen wir uns dort auf dem hochsensiblen Gebiet der realen und gefühlten Sicherheit im Straßenverkehr. Die explodierende Vielfalt technischer Möglichkeiten, man denke zum Beispiel an frei im Fahrzeugraum schwebende holografische Anzeigen, die durch Handbewegungen bedient werden, stellt die Entwickler vor neue Herausforderungen: Wie gewährleiste ich in einer von Augmented Reality bestimmten Zukunft, dass eine Fehlbedienung ausgeschlossen ist?

Autohersteller sind nicht nur deshalb gut beraten, bei der Entwicklung von HMISystemen viel Energie auf die Sicherstellung der Funktionsweise und Kundenakzeptanz zu verwenden. Denn Nutzer eines Fahrzeugs werden von agierenden
Personen zu Objekten, die von Kameras und Sensoren durch ihren fahrenden Untersatz überwacht werden, überwacht werden müssen. Auf allen Ebenen des automatisierten Fahrens bis SAE-Level 5 wird es nämlich notwendig sein, dass die Technik über den jeweiligen Status des Fahrers im Bilde ist. Nur so kann eine sichere Übergabe der Fahrverantwortung bewerkstelligt werden, wie dies die IAV in ihrem Fachbeitrag behandelt.

Das Lateinische „assistere“ heißt „unterstützen“. Ein Assistenzsystem - auch und gerade eines im Auto - darf also niemals zu einem Big Brother werden, der seine Schutzbefohlenen bevormundet. Gleichwohl wird man sich aber in mancherlei Belangen von der Weisheit „Vertrauen ist gut - Kontrolle ist besser“ verabschieden müssen, da die Kontrolle schlichtweg komplett an die Technik abgegeben ist. Und soweit es die reinen Fahrfunktionen betrifft, dürfen wir uns darauf auch schon sehr freuen.

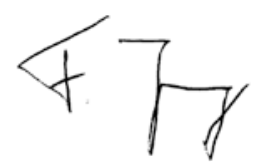

Frank Jung

Redakteur

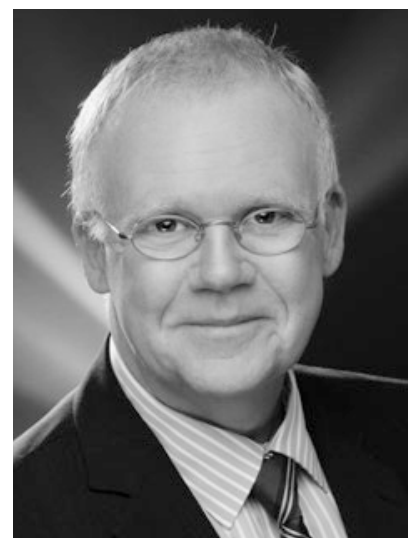

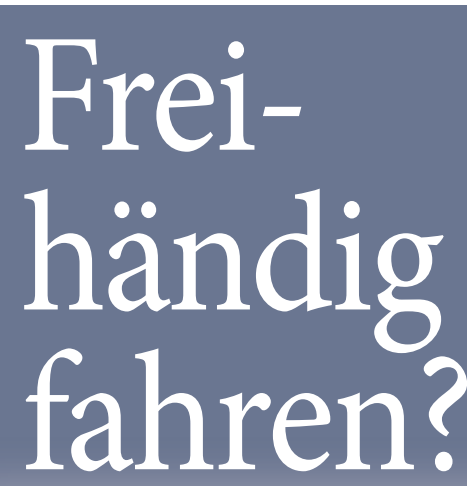

Alles eine Frage der Methode.

Fahrerassistenzsysteme verändern das Auto. Stark vernetzt und zunehmend offen können die sicherheitskritischen Helfer jedoch auch Etabliertes ins Wanken bringen. Für die richtige Balance vereinen wir Systems Engineering, Safety und Security sowie intelligente Testmethoden zu einem funktionsorientierten Gesamtkonzept. Und damit Sie noch mehr Wege erkunden können, sind unsere Lösungen skalier- und wiederverwendbar.

ITK Engineering GmbH - Ihr methodischer Partner für mehr Fahrfreiheit.

www.itk-engineering.de

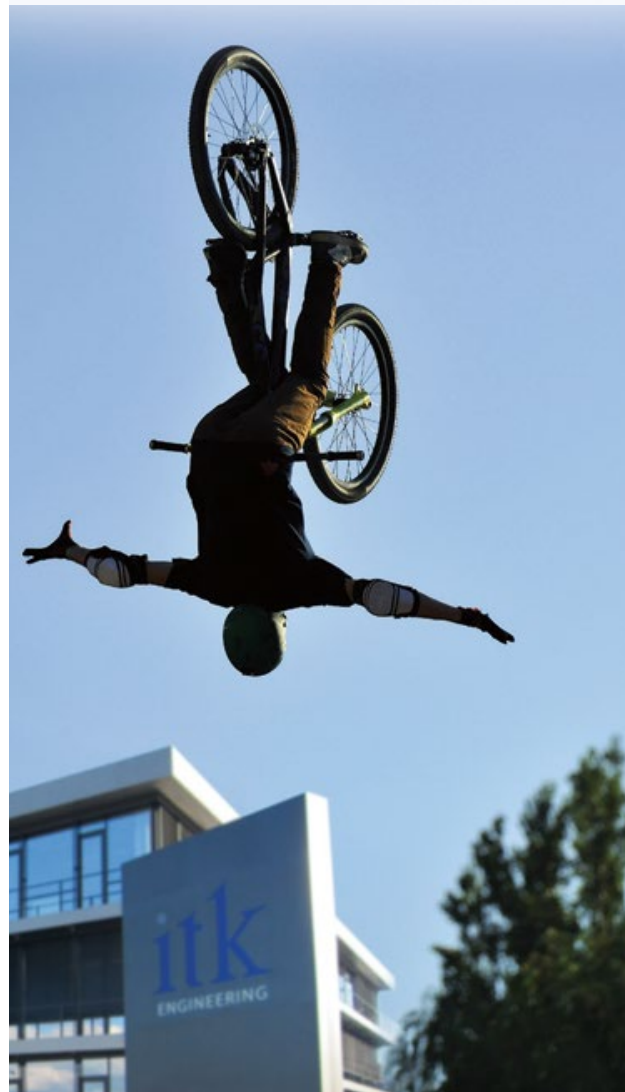

